\title{
ESTIGMA EM RELAÇÃO AOS EGRESSOS DO SISTEMA PENITENCIÁRIO
}

\section{STIGMA IN RELATION TO THE EGRESS FROM THE PRISON SYSTEM}

\author{
Gilson Cássio de oliveira Santos, \\ Doutor em Sociologia (2016) pela Universidade Federal de Minas Gerais \\ (UFMG).Mestre em Desenvolvimento Social (2009) e Bacharel em Ciências Sociais \\ (2005) pela Universidade Estadual de Montes Claros. Brasil. \\ E-mail: gilson.santos@unimontes.br \\ Ana Paula Santos Corrêa, \\ Bacharela em Direito pela Faculdade Santo Agostinho, Brasil. \\ E-mail: anapauula79@hotmail.com
}

Recebido: 10/11/2020 - Aceito: 27/11/2020

\section{Resumo}

O presente trabalho tem como objeto a avaliação do estigma imputado tanto aos apenados quanto aos egressos do sistema penitenciário. Através de pesquisas bibliográficas, debouçou-se sobre a função da Lei de Execução Penal consoante ao Sistema Carcerário brasileiro, de modo a observar se o texto legislativo é coerente com a realidade prática e quais as consequências do cárcere no processo de ressocialização. Verificou-se a ligação existente entre o egresso, o trabalho, a família e reincidência criminal, de modo a desvendar a existência do estigma e quais as consequências da estigmatização.

Palavras-chave: Estigma; exclusão social; sistema penitenciário.

\section{Abstract}

The present work aims to evaluate the stigma attributed to both inmates and graduates of the prison system. Through bibliographicalresearch, it was verified the function of the Law of Criminal Execution according to the Brazilian Prison System, in order to exemplify whether the legislative text is consistent with the practical reality and what the consequences of prison in the process of resocialization. Last but not least, there wasa link between thegraduate, work, family and criminal recidivism, in 
order to unravel why there is stigma and what the consequences of stigmatization are. Keywords: Stigma; social exclusion; prison system

\section{Introdução}

O objeto do presente trabalho é o estudo acerca do apenado e do ex-detento com fulcro na estigmatização a fim de desvendar o seu porquê e os impactos que esse estigma pode causar na vida do egresso, seja em âmbito individual ou coletivo. Buscou-se exemplificar os fatores e as consequências que o cárcere desempenha na vida do detento e do egresso.

Desde tempos pré-históricos os indivíduos se dividem em grupos, cuja convivência desenvolveu a chamada socialização, que nada mais é do socializar-se, interagir com o outro, estar em contato com pessoas conhecidas ou não. Foi a partir dessa interação que surgiram os critérios de convivência, ou padrões de conduta.

Embora pareçam positivos, os padrões de conduta desenvolvidos ao longo dos anos trouxeram à tona sérias consequências negativas. Uma delas é o estigma. Fala-se em consequência, pois os padrões desenvolvidos são vistos como regras, leis que devem ser seguidas a qualquer custo e preço, de modo que o seu descumprimento acarreta sanções formais ou informais. É sabido que os indivíduos constantemente punidos geralmente são estigmatizados como transgressores (FOUCAULT, 2013).

Em síntese, é possível afirmar que os padrões de conduta produzem mais do que regras, como também etiquetamento humano, estigmatização, e, consequentemente, a exclusão social do agente estigmatizado. No sistema penitenciário se percebe tais marcas sociais, uma vez que no interior das prisões, os indivíduos lá inseridos passam por um processo enfático de opressão. Enquanto deveriam ser ressocializados, são ainda mais segregados e rotulados, ou seja, estigmatizados como pessoas que devem permanecer distantes das atividades sociais corriqueiras. 
Apresentando sérias dificuldades na reinserção individual nas práticas cotidianas, as prisões acabam efetivando um ciclo vicioso funcionado da seguinte forma: recebem os infratores, os excluem do convívio social sem ressocializá-los, os devolvem para o seio social, que por sua vez, não os insere nos processos e práticas convencionais, mantendo a exclusão inicial ou agravando-a. Tornando-os, assim, excluídos mesmo quando ao término da pena.

\section{Observações sobre o estigma}

Os indivíduos tendem em agir conforme parâmetros e normas sociais, em razão do fenômeno da socialização. Entretanto, aos olhos da sociedade ocidental, para manter uma sociedade organizada se faz necessário também a existência de sanções, como meio de coibir o descumprimento das normas, sejam tais sanções penais ou restitutivas (DURKHEIM, 2015).

O estigma pode ser definido como uma marca deletéria atribuída ao indivíduo em razão do seu comportamento ou sua vinculação a um determinado grupo não integrado ao padrão estabelecido. Trata-se de uma desvalorização da pessoa, da sua imagem como integrante da sociedade. O estigma pode ser entendido também, como uma desvantagem, um defeito ou uma fraqueza. Nas palavras de Giddens (2017, p.

248) o estigma "são características físicas ou sociais identificadas como humilhantes ou que sejam socialmente reprovadas, resultando em ignomínia, distância social ou discriminação". A partir dessa concepção há uma distinção dos indivíduos, entre os normais e os estigmatizados/anormais. Os normais são as pessoas humanas "perfeitas", que seguem os padrões, já os anormais são vistos como humanos incompletos, vez que subvertem os padrões (BACILA, 2015).

No decorrer dos anos o estigma alcançou duas dimensões, uma objetiva e outra subjetiva. A primeira se refere aos aspectos físicos, como a cor, a orientação sexual, vícios, status e outros. Já a segunda se refere a qualificação que se dará aos aspectos da dimensão objetiva, por exemplo, se a pessoa é deficiente físico quer 
dizer que ela é inferior ou ruim quando comparadas com outras que não o são. Essa dimensão alcança justamente a ideia dos normais e estigmatizados, na qual os deficientes são os estigmatizados, enquanto os não deficientes são os normais (Idem).

Quando se distingue as pessoas por suas qualidades ou condições físicas vêse uma clara construção de parâmetros e regras de convivência, pois há uma limitação da integração social e consequentemente da socialização. Trata-se, portanto, de um fator de exclusão social. Estas regras são também denominadas de metarregras, pois além de serem regras não regulamentadas pela Lei, operam como formas de discriminação (Idem).

A compressão dos estigmas como metarregras para a sociedade simplifica muito a forma de lidar com o problema da seleção de pessoas e pode servir como base para estudos de instituições que atuam com metarregras/estigmas (policial, juiz, promotor, advogado, etc), além de poder trazer outras perspectivas para solucionar questões que afetam a teoria geral do direito, pois de que adianta interpretar regras formais sem ter em consideração as metarregras (estigmas)? (BACILA, 2015, p. 136).

Quando o estigma e as metarregras são analisadas pela mesma ótica, percebe-se uma nítida simplificação do estudo do próprio estigma, o que possibilita novas discursões em diversos níveis. O estigma como metarregras pode ser divido em algumas modalidades, como: da mulher, da pobreza, da raça não predominante, da religião. (GIL, 2011).

É importante frisar que, na antiguidade o estigma fazia referência a sinais corporais, como os cortes ou marcas de fogo. Os sinais tinham o objetivo de evidenciar fatos, assim, quem os carregava era digno de desprestigio social, a exemplo dos traidores, criminosos ou escravos, marcados fisicamente de algum modo para identificar sua inferioridade em relação ao padrão social (GOFFMAN, 2004).

O indivíduo estigmatizado pode tentar modificar a sua condição ou simplesmente aceitá-la. Quando o indivíduo decide aceitar essa condição, tem-se uma grande preocupação, pois, imagine que determinada pessoa foi considerada culpada por um ato ou crime que não cometeu, haverá rejeição, seletividade, 
preconceito ou a depender do grau da discriminação o indivíduo que era inocente poderá ser o mais novo integrante do crime (Idem).

O etiquetamento é uma consequência da prática de comportamentos que são considerados desviantes pela sociedade e/ou pela lei. O etiquetamento varia de acordo com o impacto social, e isso irá depender de quem é o delinquente, pois se de um lado há uma pessoa rica que furta, ela terá uma assistência profissional, familiar e até apoio dos amigos. Por outro lado, se o delinquente é um indivíduo de classe baixa será castigado por ser pobre, e pobre aos olhos preconceituosos da sociedade capitalista ocidental, tem tendências a prática delituosa. Em outras palavras, é possível afirmar que status social possui o condão que distingue o caráter do indivíduo, bem como a sua pena (BACILA, 2015).

"Se um indivíduo só é aceito numa comunidade específica, adivinhe se ele vai seguir as regras desta comunidade. Provavelmente se tonará o seu maior defensor" (BACILA, 2015, p. 33). De tal forma, é possível aferir que o estigma é fator determinante no futuro do indivíduo, pois embora ele cumpra a sua pena, esta nunca será suficiente para a sociedade, dado que o estigma é uma marca quase indelével. Tal marca que se perpetua por vários motivos, e um deles é causado pelo próprio estigmatizado, que por muitas vezes aceita o tratamento diferenciado ao invés de se impor ou de se enxergar como um estigmatizado. É como se a vítima aceitasse ser vítima (ldem).

Importante pensar que, aceitando ou não ao estigma, este é imposto pela sociedade ao indivíduo, de modo que o estigmatizado não tem muitas alternativas de romper com a forma pela qual é avaliado pela sociedade. A consequência mais severa do estigma se materializa na exclusão social, por exemplo: na impossibilidade de se obter respeito entre os demais indivíduos, na dificuldade de se relacionar pessoalmente e na ausência de ingressar em uma vaga de emprego.

\section{O Sistema Prisional e a Lei de Execução Penal}


A Execução Penal no Brasil é disciplinada pela Lei 7.210 de julho de 1984, também denominada Lei de Execução Penal (LEP). Antes da sua implementação em 1984, houve um projeto para a implementação do Código Penitenciário da República em 1933, elaborado por Cândido Mendes, Lemes de Brito e Heitor Carrilho. O projeto vislumbrava codificar as normas de execução penal, que já se faziam necessárias, pois o sistema prisional se encontrava repleto de falhas e com extrema dificuldade na aplicação das penas, tanto privativas de liberdade, quanto as de medida de segurança. Todavia, o projeto foi abandonado, assim, como muitos outros, (MARTINS, 2018).

O abandono se deu porque em 1937, houve a instituição do regime do Estado Novo, que suprimiu o exercício dos congressistas inviabilizando o prosseguimento do projeto. Lado outro, em 1970 foi apresentado um novo projeto que disciplinava regras mínimas de tratamento aos detentos, porém o mesmo não vingou (OLIVEIRA, 2018).

Em 11 de julho de 1984 publicou-se a Lei no 7,210, chamada de Lei de Execução Penal (LEP). Pode-se dizer que a LEP tem por objetivo executar as decisões criminais ou as sentenças proferidas pelo judiciário buscando uma harmonia entre o comportamento humano e a lei propriamente dita, com enfoque no condenado e em sua ressocialização (MARCÃO, 2014).

Nesse sentido dita 0 art. $1^{\circ}$ da referida lei:

Art. $1^{\circ}$ a execução penal tem por objetivo efetivar as disposições de sentença ou decisão criminal e proporcionar condições para a harmônica integração social do condenado e do internado (BRASIL, Lei $n^{\circ} 7.210$, 1984).

Frente ao exposto, é possível auferir que a LEP buscou de antemão garantir que os seus preceitos fossem integralmente cumpridos, de modo que o detento pudesse receber o tratamento adequado, pois entende a mesma que a reinserção social vincula-se diretamente ao cumprimento da pena (MARTINS, 2018). Em outra perspectiva, busca a LEP efetivar as decisões que fundiram em Juizados Especiais e sentença penal, seja ela condenatória ou absolutória, na qual a pena não busque tão somente a condenação, mas sim a humanização do preso (MARCÃO, 2014). 


\title{
Revista Multidisciplinar do Nordeste Mineiro, 2020/02 \\ ISSN 2178-6925
}

\begin{abstract}
A obrigatoriedade de um processo penal executório (ou processo de execução penal) corresponde as exigências de autonomia cientifica do Direito de Execução Penal e a Lei de Execução Penal deve constituir-se em instrumento adequado para que a jurisdição se amplie se concretize nessa zona juridicamente neutra, máxime quando se contar com uma Magistratura especializada para descumprir dessa importante função (MIRABETE; FABBRINI, 2017, p. 5).
\end{abstract}

Ademais, para a aplicabilidade da execução penal, é preciso desde logo de um título executivo judicial, ou seja, de uma sentença, na qual precisa dispor sobre medidas de segurança (sentença imprópria), penas privativas de liberdade ou restritivas de direito (OLIVEIRA, 2018). Ante todo o exposto, verifica-se que a LEP, é na verdade fruto de tentativas que se mostram falhas ao longo dos anos. Embora sua criação tenha originado em decorrência de projetos que não vingaram, a Lei de Execução Penal figura-se de forma sólida como uma carta que prevê um sistema prisional mais brando, humano, digno e que acima de tudo, que possa humanizar o apenado na tentativa de propiciar sua reinserir na sociedade.

No tocante especificamente ao Sistema Penitenciário Brasileiro é importante ressaltar suas falhas quanto a capacidade de absorção da demanda. As prisões brasileiras são historicamente superlotadas com uma tendência de elevação da superlotação.

\begin{abstract}
Em um manifesto aprovado pela unanimidade dos presentes ao VII Encontro Nacional de Secretários de Justiça, realizado nos dias 17 e 18 de junho de 1991, em Brasília, foi dito que havia no Brasil, segundo o Ministério da Justiça, milhares de mandatos de prisão aguardando cumprimento, e que as prisões, em todos os estados da federação, estavam superlotadas, o que comprometia o tratamento do apenado e pavimentava o caminho para a reincidência (LEAL, 2001, p. 57).
\end{abstract}

Conforme já mencionado, a execução penal não se restringe apenas em cumprir o que se dispôs na sentença, há também uma preocupação em impedir uma futura reinserção do egresso, para tanto, contudo, é de suma importância que haja a individualização da pena. Porém, o sistema prisional vem enfrentando inúmeras dificuldades, a exemplo da superlotação, o que impede que haja uma harmonia entre a lei propriamente dita e a sua função (LEAL, 2001). 
Com relação a individualização da pena, cabe enfatizar o disposto no art. 26 da LEP, preceituando que os presos devem ser distribuídos no sistema prisional conforme uma ordem de classificação, de modo que cada um conviva diretamente com detentos do mesmo escalão. Ou seja, o que se pretende é que haja uma análise da gravidade do crime, dos antecedentes, bem como da personalidade, a fim de evitar que o preso se corrompa mais. Logo, não se pode falar em individualização da pena, se não houver a classificação dos detentos (LEAL, 2001).

Nesta senda, questiona-se, caso essa individualização fosse adequada, teria o sistema prisional brasileiro uma estrutura suficiente para a sua aplicação? Se não, por quê? Em síntese, é possível dizer que as prisões não possuem suporte para tanto, visto a falta de investimento, de profissionais qualificados, de estrutura, dentre outros fatores, o que corrobora para a atual falência do sistema (LEAL, 2001).

É possível afirmar que a tentativa do Direito Penal em reduzir a criminalidade e reinserir o delinquente na sociedade demonstrou-se falha ao longo dos anos, haja vista os elevados índices de criminalidade. Essa tentativa é na verdade, um meio para promover uma convivência social harmônica (OLIVEIRA, 2018).

Em 2006 o Departamento Penitenciário Nacional-DEPEN, informou que a população carcerária brasileira era de 361.402 e que as prisões comportavam apenas 206.347 presos. Destaca-se que entre 1995 e 2005, houve o crescimento de 95\% dessa população, que fez com que a prisão deixasse de transparecer e executar o caráter primordial da pena, pois além de excluir o condenado da sociedade não havia um cumprimento digno da sentença, como ressalta a Constituição da República Federativa do Brasil de 1988 (CAMARGO, 2018).

Já em agosto de 2018, a Ministra Cármen Lúcia apresentou ao Conselho Nacional de Justiça (CNJ) uma nova pesquisa feita pelo Banco Nacional de Monitoramento de Presos (BNMP 2.0), que identificou parcialmente a atual população carcerária no Brasil. Segundo o estudo há cerca de 602.217 presos, dos quais $95 \%$ são homens e apenas $5 \%$ são mulheres e que dentre estes, cerca de $40 \%$ são presos provisórios e $27 \%$ respondem por roubo, conforme matéria publicada pelo site Justificando (CNJ, 2019). 
Nesse sentido, é importante ressaltar que o art. 85 da LEP dispõe sobre a necessidade de o estabelecimento prisional suportar a quantidade de presos dentro da sua capacidade de espaço. Devendo, portanto, haver compatibilidade entre a lotação, estrutura e finalidade. Salienta o art. 85 da referida lei que o condenado deve cumprir sua pena em cela individual, mas na realidade o mesmo não ocorre (BRASIL, Lei $n^{\circ} 7.210,1984$ ).

Frente aos dados é possível aferir que o sistema prisional atualmente está em estado de superlotação, sendo um verdadeiro deposito humano, carece de vagas e de infraestrutura. Todavia, não se pode dizer que o problema se resolve com a construção de novas prisões, uma vez que o déficit não é só na estrutura do sistema, há que se observar também inadequação da questão de gestão e o desinteresse estatal.

Em uma entrevista, no ano de 2012 o Ministro da Justiça José Eduardo Cardoso, afirmou que se fosse condenado a pena privativa de liberdade que era preferível morrer, e mais, disse que aprisionar um réu primário em meio a tantos criminosos, é quase inevitável que ele saia de lá como entrou. Ressaltou ainda a possibilidade de o detento sair como integrante de uma facção ou organização, fugindo inclusive das escolhas individuais do próprio preso (FERNANDO, 2018).

Mediante a este panorama é possível inferir sobre a necessidade de intervenção do Ministério Público nos sistemas prisionais, pois embora a pena deva ser cumprida, isso não significa que necessite de cumprimento a qualquer custo. Como leciona o art. $5^{\circ}$ caput, e inciso XLIX da CRFB/88, todos são iguais perante a lei, assim é de responsabilidade do Estado assegurar o mínimo de dignidade aos detentos (FERNANDO, 2018).

Em uma análise mais profunda e crítica, é possível dizer que a prisão tem sido um fracasso, pois mesmo após cento e cinquenta anos da sua existência não se pode afirmar que o sistema é adequado e eficiente ao ponto de alcançar o caráter humanitário. Ocorre na verdade a manutenção da delinquência e uma clara indução da reincidência. Destaca-se que mesmo após o cumprimento da pena, o egresso 
ainda é cobrado pela sociedade por atos passados, logo, a pena/prisão possui uma duplicidade de consequências.

Em setembro de 2014, foi publicado no El País, informações acerca da rotina no Complexo Penitenciário de Pedrinhas Maranhão, a publicação teve como base depoimentos de um funcionário do complexo há mais de 15 anos. O complexo virou destaque nas redes sociais, após a publicação de imagens, tiradas pelos próprios detentos, que mostravam presos mortos no pátio do local (BEDINELLI, 2018).

Relatou o funcionário que o complexo é segregado entre facções, que as mesmas comandam suas operações de dentro do estabelecimento. Via-se telefone celular, mesmo havendo constantes revistas e apreensões. Ressaltou ainda que é inacreditável a quantidade de celulares que eram aprendidos, e mais, frisou que as condições e estrutura do complexo são péssimas (Idem).

Após a rebelião no Complexo Penitenciário Anísio Jobim-COMPAJ, em Manaus, que resultou na morte de cinquenta e seis detentos, o presidente Michel Temer e o ministro da justiça Alexandre de Moraes, à época, anunciaram uma medida que direcionaria $R \$ 430$ milhões para melhorar a segurança dos presídios, bem como para construir outros (SOUZA, 2018).

Diante disto, apontou o ministro do Supremo Tribunal Federal (STF), Gilmar Mendes, em entrevista à BBC Brasil, que a crise penitenciaria brasileira não se resolve com a construção de mais presídios. Afirmou ainda, nos dizeres de um padre, que havia visitado o presídio que o complexo de Manaus é na verdade uma fábrica produtora de violência e propagadora da tortura (SOUZA, 2018).

Em análise geral, deve-se dizer que a instituição da LEP foi além da punição, vislumbrou-se de imediato a proteção do preso com fulcro em direitos e deveres, sob a égide de preceitos fundamentais, de modo a zelar pela coesão entre a lei e sua real aplicação. Todavia, na prática, com o decorrer dos anos, embora robusta, a lei demostrou-se bastante frágil, cedendo espaço a violência, principalmente quando verificada a superlotação.

Esta trouxe à tona uma realidade ainda desconhecida por muitos brasileiros, de um lado houve o impacto informativo, mas de outro a consciência de um 
problema. Em linhas gerais é possível afirmar que a aplicação da LEP e a atual situação carcerária são cruciais no desenvolvimento do preso, principalmente quanto a pessoa do egresso. Pois embora não pareça, o ambiente do cárcere, assim como o modo de cumprimento da pena são circunstâncias que refletem diretamente na pessoa do condenado e do egresso do sistema prisional.

\section{Observação sobre a ressocialização}

O termo ressocialização embora certo quanto ao seu caráter e abordagem, é diferente no que tange ao alcance e resultado. Isto é, a efetiva ressocialização do egresso não se limita ao cumprimento da pena, mas aos fatores externos que são condições fins para a reinserção social. Efetivar, pois o modo de execução da pena, é fator meio para que o egresso possa alcançar o patamar de ressocialização, de se sentir ressocializado. Logo, a ressocialização é um processo que contempla questões relativas às liberdades e interação individuais e que perfaz sobre a aplicação da LEP, havendo, portanto, a atuação estatal direta (MADEIRA, 2004).

Embora haja previsão legal acerca dos direitos e garantias dos presos e egressos, estes não desfrutam de todo o aparato legislativo, pois ainda que a legislação expressa na LEP se apresente robusta, é certo de que a sua aplicação ocorre de forma diferenciada (SANTOS, BARBOSA, LIMA, CASSUNDÉ, 2018).

A reinserção social não se restringe apenas a correção da prática delitiva, avalia-se sim questões relacionadas ao cumprimento formal da pena, mas também ligadas ao acolhimento social e familiar. Desta forma, tem-se que a falta de emprego, salário desproporcional, rejeição individual, dentre outros, são cumulativamente ou isoladamente fatores determinantes para a reiteração delitiva (Idem).

Dentre outros dispositivos leciona o art. 10 e parágrafo único da LEP que o preso, assim como o interno possuem, ambos a garantia de prevenção ao crime, bem como de retorno ao ambiente social (MADEIRA, 2004). "A reinserção social é proposta ao apenado por intermédio de uma série de abordagens de assistência, ou tratamento penal, com o intuito de promover a possibilidade de devolução deste 
individuo recluso a sociedade" (SANTOS; BARBOSA; LIMA; CASSUNDÉ, 2018, p. $\mathrm{s} / \mathrm{n})$.

O cárcere pode ser definido por diversas formas, para alguns detentos e egressos, prisão é sinal de morte em vida, de vulnerabilidade, representa trauma, sofrimento, solidão, humilhação e arrependimento. Porém, para outros, a prisão é vista como instrumento necessário, e mais, é tempo para refletir o erro, mas para tanto alertam a necessidade de reeducação do preso (IPEA, 2015).

Em estudo realizado pelo Instituto de Pesquisa Econômica aplicada, no ano 2015, um condenado em regime fechado informou em depoimento que a prisão necessita de cuidados urgentes. Narrou também que sem a prisão o mundo seria um caos. Porém, questiona-se quanto a interação dos presos, ou melhor, quanto a segregação entre os presos. A realidade atual mostra que um homicida geralmente cumpre pena na mesma cela que um ladrão comum. E mais, o referido condenado destacou que essa convivência muda a pessoa e sempre para pior, dificultando ainda mais sua reinserção (Idem).

Uma das grandes dificuldades enfrentadas pelos detentos que querem trabalhar são as questões relacionadas ao trabalho e sua disponibilidade. Em depoimento dispôs um condenado: "falta muita oportunidade dentro do sistema prisional (...). Falta muita coisa para a pessoa virar um reeducando mesmo [...]. Falta muito mesmo: é superlotação, falta mais espaço para o preso, falta uma assistência social" (IPEA, 2015, p.105).

As dificuldades não se encerram com as falas, pois, a ausência de trabalho reflete muito além de mera ocupação do tempo ou diminuição da pena, uma vez que umas das principais funções do cárcere é justamente a ressocialização do indivíduo. Ou seja, é o cárcere meio preparatório de reflexão, assim pensam alguns presos (IPEA, 2015).

Há de se ressaltar que o cumprimento da pena pode ser em si condição determinante para a reincidência ao crime, pois caso a reclusão seja de forma indigna ou o egresso não seja acolhido socialmente haverá grande probabilidade de reiteração delitiva (TOLEDO, 2012). Ante todo o exposto, verifica-se que a 
ressocialização nada mais é do que um processo que se inicia no sistema prisional, mas se concretiza apenas quando retorna ao convívio social.

Depreende-se, portanto que a ressocialização possui grau triplo de relevância, quais sejam: individual, social e jurídico. Individual, pois é capaz de transformar o indivíduo; social, pois toda conduta humana tem o condão de influenciar fatos e ações de outrem; jurídico, pois quando a ressocialização é efetiva dificilmente haverá reiteração delitiva. Porém, todo o processo depende de como se dará o cumprimento da pena.

\section{Trabalho: oportunidade ou exclusão?}

Dispõe o art.27 e 28 da LEP que o trabalho além de ser um dever social é condição de dignidade humana, pois busca-se a educação e produção do egresso, mas que para tanto é necessário a interferência do serviço de assistência social, de modo a facilitar a obtenção do trabalho. O trabalho cumpre desde a antiguidade o papel de

moldar o indivíduo e de desenvolvê-lo socialmente, "é pelo trabalho que o ser humano se distingue das formas não humanas e se torna um ser social" (TOLEDO, 2012, p. 17).

Ante o exposto, é necessário lembrar que trabalho atua como meio de reinserção social, em detrimento das relações supervenientes. A importância do trabalho verifica-se claramente no art. 114, inciso I da LEP, vez que um dos requisitos para o ingresso no regime aberto é estar trabalhando ou comprovar a possibilidade de fazê-lo (BRASIL, Lei n $7.210,1984$ ).

Porém, nem sempre o acesso ao trabalho é tarefa fácil quando se cumpre uma pena privativa de liberdade. Quando o egresso encontra emprego ao sair do cárcere tem-se o início da ressocialização, mas e quando o trabalho se torna inacessível pelo simples fato de ser ex-detento? (TOLEDO, 2012).

O trabalho é um recomeço, uma interação social capaz de criar vínculos e estabelecer relações, principalmente quando não há o apoio familiar. Em ausência 
do apoio familiar o trabalho enquadra-se como a última chance de sobressair a condição de ex-detento. Por esta razão, contemplam estudiosos que o trabalho não deve ser apenas uma preocupação individual, mas sim da coletividade, já que a condição de preso não é eterna (TOLEDO, 2012).

Partindo da análise e da perspectiva que o trabalho é instrumento necessário para a reinserção social, cabe destacar a criação da Fundação de Apoio ao Egresso do Sistema Prisional (FAESP) no Estado do Rio Grande do Sul. Tal projeto se iniciou a partir da Campanha da Fraternidade: "A Fraternidade e os Encarcerados", cujo enfoque era o abandono do detento e o estigma que o egresso e família enfrentam (MADEIRA, 2004).

Dentre os vários objetivos da Fundação, destacou o trabalho. Atuava a mesma de forma direta e ativa, intermediando a relação ex-detento e empresa, a fim de ofertar emprego aos egressos em liberdade condicional. A conexão se dava meio do Projeto Vida Nova e da Cooperativa Laborsul, que disponibilizou vagas exclusivas para egressos, a fim de ser ponto de ligação entre estes e o trabalho (MADEIRA, 2004).

O Projeto Vida Nova, também chamado de convênio FAESP-DETRAN, constituído em 2002, buscava garantir ao egresso ao menos um trabalho temporário ao sair do cárcere, e para tanto disponibilizou 20 (vinte) vagas para os expresidiários. Foram mais de 50 (cinquenta) egressos a procura da Fundação. A Fundação não se preocupava apenas com o trabalho, havia olhares e projetos diversos, desde a educação até cursos profissionalizantes. Embora extraordinário o trabalho realizado pela Fundação, sua atuação não era de grande alcance, faltavam recursos para investir, para acompanhar os egressos pontualmente, principalmente quando o trabalho conveniado chegava ao fim (MADEIRA, 2004).

No decorrer dos anos verificou-se que o trabalho por si só não era suficiente para que o egresso se sentisse reinserido socialmente. Preocupava-se também com a remuneração que era ofertada e com a atenção familiar despendida. Afirmaram alguns egressos que ter um trabalho não significa haver satisfação pessoal ou ressocialização, muitos chamam atenção para o suporte familiar, dispondo que esta é também um dos inibidores da reincidência (SARON apud TOLEDO, 2012). 


\section{Revista Multidisciplinar do Nordeste Mineiro, 2020/02 \\ ISSN 2178-6925}

No tocante a família é importante ressaltar os seguintes depoimentos citados por Toledo (2012, p.54):

Estava trabalhando com meu tio, entendeu? Trabalhei com ele um mês e pouco, de servente também. Aí eu vim pra cá. Aí o meu tio conheceu um rapaz que trabalhava aqui, aí ele ligou pra esse rapaz pra eu vim fazer entrevista. Aí no mesmo dia pediram pra eu trazer tudo pra me fichar já. (Gl)

É, os antes foram um bico. Eu estava lá no C., estava num negócio de cimento lá, mas aqui é uma coisa mais... É meu primeiro trabalho de carteira assinada. (Wn)

Não, eu trabalhei com o meu tio particular também. (CC)

Aí fui e me ofereceu um serviço. Aí quando falou que era servente, eu já fiz de tudo, aí eu fui e aceitei, eu vim pra cá. (F)

É meu primeiro trabalho. Depois que eu saí da prisão eu fiquei uns oito meses procurando emprego. (G)

O meu irmão que já ralava aqui foi e me indicou para o encarregado. (A)

É, o primeiro. Eu fui saindo da prisão e fui vindo pra cá. Eu tenho um cunhado aqui que me encaminhou. Ele trabalha aqui e conhece $o$ encarregado. Aí ele pediu pra eu vim aí. (J L)

(...) depois que eu saí de lá é a primeira empresa. (W) (TOLEDO, 2012, p. 54).

Nesta senda, em análise inicial, verifica-se que os egressos enaltecem o trabalho adquirido citando sempre os seus familiares. Percebe-se também que embora exista o suporte familiar ainda sim recorrem ao trabalho, mesmo que informal, pois querem mostrar que merecem outra chance, mas acima de tudo buscam ser aceitos pela sociedade (TOLEDO, 2012).

Ademais, é nítido que os depoentes não possuem grau elevado de escolaridade, dificultando acesso a vagas de trabalho. Não que isso venha a justificar a prática delitiva, pelo contrário, mas apenas confirma que a desigualdade foi e continua a ser fator determinante no índice de criminalidade e violência (TOLEDO, 2012). 


\section{Reincidência: estigma e o retorno a prisão}

Reincidência, como o próprio nome aduz vem de reincidir, fazer de novo. Em termos jurídicos, leciona o art. 63 do Código Penal que a reincidência se verifica quando um indivíduo comete novo crime após o trânsito e julgado de crime anterior, seja em seu país ou no estrangeiro (BRASIL, Decreto-Lei no 72.848, 1940).

Todavia, existem divergências quando a concretização da reincidência, isto é, a reincidência criminal pode ser definida de seis formas, sendo elas: reincidência penitenciária, que é o ato de retornar ao sistema prisional; reincidência policial, quando ocorre um registro criminal de um mesmo agente por fato novo; reincidência por autoculpa, quando o próprio indivíduo se declara reincidente; reincidência judicial, que é a condenação de uma pessoa por outro crime; reincidência penal, que é a existência de novo julgamento e por fim tem-se a reincidência jurídica, que é o julgamento de uma mesma pessoa por outro crime descrito no Código Penal (SAPORI; SANTOS; MAAS, 2017).

A reincidência é decorrente de inúmeros fatores, sejam eles pessoais ou coletivos. Inicialmente cabe ponderar que a reincidência está diretamente ligada com a reinserção social, um grande exemplo, são os fatores pessoais, pois como já abordado, a ressocialização não depende da voluntariedade do egresso em querer se reintegrar (SAPORI; SANTOS; MAAS, 2017).

Os aspectos coletivos e estatais possuem diretrizes, estas que vão desde o cumprimento da pena, à assistência familiar e comunitária. Fala-se do cumprimento da pena, pois o sistema carcerário é visto atualmente por unanimidade como a escola do crime, já que as penitenciarias estão superlotadas, não há trabalho para todos os detentos, assim como inexiste sequência educacional nas prisões. Há na verdade um desrespeito ao preceito fundamental da dignidade da pessoa humana (MADEIRA, 2004).

Nesse sentido percebe-se que embora seja a Lei de Execução Penal, séria e robusta, não possui a mesma aplicação direta e eficaz, é notório a existência de falhas no sistema e a má gestão do mesmo. Não há o caráter humanístico como 
dispõe a lei, pelo contrário, os detentos, saem em sua maioria envolvidos com facções, e muitas vezes contra a própria vontade.

Nesta senda, é necessário destacar o papel da sociedade e a atuação estatal. Em entrevistas dispuseram os egressos que a vida após a prisão é extremamente difícil, principalmente no que tange ao trabalho, vez que o cárcere dificulta esse alcance, assim como uma remuneração justa, pois quando há trabalho, normalmente são informais, cuja mão de obra é muito barata (TOLEDO, 2012). Esta circunstância confirma mais uma vez o tema tratado em sessões anteriores, o estigma, que ainda é uma das maiores dificuldades enfrentadas pelo egresso, se não a maior, no que tange ao ingresso ao trabalho, por exemplo.

Por outro lado, dispõem os egressos que o acolhimento familiar é extremamente relevante. Além de facilitar a reinserção, tem o condão de inibir a reincidência, principalmente quando o egresso é pai, pois querem ver o filho crescer e conviver com a esposa. Em outras palavras, a família atua como um pilar importante para o egresso. É o fator que o liga ao mundo fora do cárcere, e estas por vezes são julgadas e humilhadas por prestarem apoio ao detento. (TOLEDO, 2012).

Mas, afinal o que determina a reincidência e qual a sua consequência? Ante todo exposto é possível afirmar com exatidão que a reincidência não contempla um fator ou outro, pelo contrário, todos, de alguma forma impulsionam a reiteração delitiva.

Embora a reincidência seja um conjunto de fatores, um deles merece destaque, o estigma. Este tem-se mostrado cada vez mais frequente na sociedade, de modo a dificultar relações e recomeços. Assim como abordado anteriormente, o estigma é uma marca inerente ao egresso em detrimento do cárcere. Inerente, mas não endógeno, pois não importa quem é a pessoa do condenado, o crime ou o tempo da pena, olha-se apenas a condição: ex-detento, e é esse olhar discriminatório que faz com que o egresso não seja acolhido socialmente e não encontre um trabalho.

Ocasionando assim, a reincidência criminal. 
Desta forma, é possível auferir que a reincidência representa nada menos do que uma cadeia de produção, pois o seu resultado (grau) varia entre o eu psíquico do egresso, o modo de cumprimento da pena e à reinserção social. Ou seja, quanto mais estigma, mais preconceito e consequentemente mais reincidência. Por fim, no que tange aos efeitos é perceptível um rompimento de vínculos. Conforme apresentado, a falta de oportunidade e/ou apoio familiar são grandes preservativos do egresso cometer novo ilícito.

\section{Considerações finais}

A Lei de Execução Penal embora robusta no que tange ao seu aspecto legislativo, demonstrou-se ao longo dos anos ineficiente quanto à aplicação de seus preceitos, em detrimento dos fins atingidos pelo sistema carcerário. Este por sua vez, tem-se apresentado cada vez mais superlotado, imputando à pena perda de um dos seus principais objetivos, a ressocialização do detento.

Percebe-se, através deste estudo que o crime, assim como a reincidência não decorrem exclusivamente de fatores intrínsecos ao agente, como a cor ou raça, temse também, as questões sociais e políticas. Socias, em razão do estigma o qual é condicionado ao egresso, e políticas, pela má gestão do sistema prisional no que tange a administração e a aplicação das leis.

O trabalho e a família demonstram-se essenciais em razão do seu significado. O egresso vê no trabalho e na família a oportunidade de ser e fazer diferente, porém, não há trabalho ou convênios suficientes para suportar todos os detentos que queiram trabalhar. Além disso, embora a família cumpra o papel de apoio, por vezes não é capaz de suprir a ausência do trabalho ou a repulsa social.

Verificou-se também que na ausência de ambas as instituições (família e trabalho) o risco a reincidência criminal é eminente, pois a ressocialização do egresso não se vincula apenas ao modo de cumprimento da pena, ela é o reflexo da exclusão social sofrida pelo indivíduo que se submeteu a privação de liberdade. 
O desafio proposto incialmente vai além das questões sociais ou do estudo generalizado do estigma, trata-se na verdade do estudo do criminoso, desde os padrões de conduta, perpassando pelo cumprimento da pena até a condição de egresso. De modo a exemplificar que estas pessoas também são parte integrante da sociedade, independentemente do que fizeram, que são dignas de respeito, assim como de recomeçar a vida. Porém, percebeu-se que a despeito do que o detento faça ou o tempo de sua condenação, a estigmatização irá se sobrepor a pessoa do apenado e do egresso, dificultando, assim a sua ressocialização e contribuindo para a exclusão e a consequente reincidência criminal.

\section{Referências}

BACILA, Carlos Roberto. Criminologia e estigma: um estudo sobre os preconceitos. 4. ed. São Paulo: Atlas, 2015.

\section{BEDINELLI, Talita. A vida deles dentro do presídio é dormir, usar droga e} comer. Disponível em:

<https://brasil.elpais.com/brasil/2014/09/26/politica/1411760527_418875.html>. Acesso em: 27 de out. 2018.

BRASIL, Código Penal. Decreto-lei 72.848, de dezembro de 1940.

BRASIL, Lei de execução penal. Lei 7.210 de julho de 1984. Brasília: Congresso Nacional, 1984.

CAMARGO, Virginia da Conceição. Realidade do sistema prisional: Mostra a realidade do sistema prisional no Brasil, que se encontra falido. Disponível em: <https://www.direitonet.com.br/artigos/exibir/2971/Realidade-do-sistemaprisional>. Acesso em: 28 de out. 2018.

CONSELHO NACIONAL DE JUSTIÇA. CNJ divulga os mais recentes dados sobre a população carcerária do Brasil. In: Justificando: mentes inquietas pensam Direito. 8 de agosto de 2018. Disponível em: $<$ http://www.justificando.com/2018/08/08/cnj-divulga-os-mais-recentes-dadossobrea-populacao-carceraria-no-brasil/>. Acesso em: maio de 2019.

DURKHEIM, Èmile. Da divisão do contrato social. Rio de Janeiro: Martins Fontes, 2015.

FERNANDO, Deivid. O papel do Ministério Público frente a situação atual do sistema prisional brasileiro: O papel do ministério público frente a situação atual do sistema prisional brasileiro. Disponível em: 
<https://deivid1234.jusbrasil.com.br/artigos/197696122/o-papel-doministeriopublico-frente-a-situacao-atual-do-sistema-prisional-brasileiro>. Acesso em: 27 de out. 2018.

FOUCAULT, Michel. Vigiar e Punir: nascimento da prisão; tradução de Raquel Ramalhete. 41. ed. Petrópolis, Rio de Janeiro: Vozes, 2013.

GIDDENS, Anthony. Conceitos essenciais de sociologia. 2.ed. São Paulo: Unesp, 2017.

GIL, Antonio Carlos. Sociologia Geral. São Paulo: Atlas, 2011.

GOFFAMAN, Ervenig. Estigma: notas sobre a manipulação da identidade deteriorada. 4. ed. 2004.

INSTITUTO DE PESQUISA ECONÔMICA APLICADA. Reincidência Criminal no Brasil: Relatório de Pesquisa. Brasília: IPEA, 2015.

LEAL, César Barros. Prisão: crepúsculo de uma era. 2. ed. ver. e atual. Belo Horizonte: Del Rey, 2001.

MADEIRA, Lígia Mori Madeira. A atuação da sociedade civil na ressocialização de egressos do sistema penitenciário. In: Anais do VIII Congresso Luso-

AfroBrasileiro de Ciências Sociais. Coimbra, Portugal, 2004.

MARCÃO, Renato. Curso de execução penal. 12. ed. rev., ampl. e atual. de acordo com a Lei n 12.850/2013. São Paulo: Saraiva, 2014.

MIRABETE, Júlio Fabbrini; FABBRINI, Renato N. Execução Penal: comentários à Lei $n^{\circ}$ 7.210, de 11-7-1984. 13. São Paulo: Atlas, 2017.

OLIVEIRA, Claudia Rafaela. Execução Penal. Disponível em:

<https://jus.com.br/artigos/63684/execucao-penal>. Acesso em: 27 de out. 2018.

SANTOS, Juliana Estevão; BARBOSA, Milka Alves Correia; LIMA, José Rodolfo Tenório; CASSUNDÉ, Fernanda Roda. Egressos do sistema prisional e a gestão de pessoas nas organizações receptora: um estudo multicasos em organização alagoanas. In: Anais do V Congresso Brasileiro de Estudos Organizacionais. Curitiba-PR, 2018.

SAPORI, Luis Flávio; SANTOS, Roberta Fernandes; MAAS, Lucas Wan Der. Fatores sociais determinantes da reincidência criminal no Brasil: $O$ caso de Minas Gerais. In: Revista brasileira de Ciências Sociais. São Paulo, v. 32, no 94, julho de 2017.

SOUZA, Felipe. A questão não se resolve com construção de presídios, diz Gilmar Mendes sobre crise penitenciária. BBC. Disponível em: 
<https://www.bbc.com/portuguese/brasil-38492779>. Acesso em: 27 de out. 2018.

TOLEDO, Isadora D' ÁVILA. O trabalho e seus sentidos para egressos do sistema prisional: estudo de uma experiencia de reinserção no mercado formal de trabalho. [Dissertação de mestrado]. Universidade Federal de São João DelRei. São Joao Del-Rei, 2012. 